\title{
Intracortical and Thalamocortical Connections of the Hand and Face Representations in Somatosensory Area 3b of Macaque Monkeys and Effects of Chronic Spinal Cord Injuries
}

\author{
Prem Chand and @Neeraj Jain \\ National Brain Research Centre, Manesar, Haryana, 122051, India
}

Brains of adult monkeys with chronic lesions of dorsal columns of spinal cord at cervical levels undergo large-scale reorganization. Reorganization results in expansion of intact chin inputs, which reactivate neurons in the deafferented hand representation in the primary somatosensory cortex (area $3 \mathrm{~b}$ ), ventroposterior nucleus of the thalamus and cuneate nucleus of the brainstem. A likely contributing mechanism for this large-scale plasticity is sprouting of axons across the hand-face border. Here we determined whether such sprouting takes place in area $3 \mathrm{~b}$. We first determined the extent of intrinsic corticocortical connectivity between the hand and the face representations in normal area $3 \mathrm{~b}$. Small amounts of neuroanatomical tracers were injected in these representations close to the electrophysiologically determined hand-face border. Locations of the labeled neurons were mapped with respect to the detailed electrophysiological somatotopic maps and histologically determined hand-face border revealed in sections of the flattened cortex stained for myelin. Results show that intracortical projections across the hand-face border are few. In monkeys with chronic unilateral lesions of the dorsal columns and expanded chin representation, connections across the hand-face border were not different compared with normal monkeys. Thalamocortical connections from the hand and face representations in the ventroposterior nucleus to area $3 \mathrm{~b}$ also remained unaltered after injury. The results show that sprouting of intrinsic connections in area $3 \mathrm{~b}$ or the thalamocortical inputs does not contribute to large-scale cortical plasticity.

Key words: brain reorganization; dorsal columns; Macaca; plasticity; ventroposterior nucleus

Significance Statement

Long-term injuries to dorsal spinal cord in adult primates result in large-scale somatotopic reorganization due to which chin inputs expand into the deafferented hand region. Reorganization takes place in multiple cortical areas, and thalamic and medullary nuclei. To what extent this brain reorganization due to dorsal column injuries is related to axonal sprouting is not known. Here we show that reorganization of primary somatosensory area $3 \mathrm{~b}$ is not accompanied with either an increase in intrinsic cortical connections between the hand and face representations, or any change in thalamocortical inputs to these areas. Axonal sprouting that causes reorganization likely takes place at subthalamic levels.

\section{Introduction}

Lesions of dorsal columns of the spinal cord at cervical levels result in deafferentation of sensory inputs from parts of the body

Received May 26, 2015; revised Aug. 24, 2015; accepted Aug. 25, 2015.

Author contributions: N.J. designed research; P.C. and N.J. performed research; P.C. and N.J. analyzed data; P.C. and N.J. wrote the paper.

This work was supported by Department of Biotechnology, Government of India Grant BT/PR7180/MED/30/907/ 2012 to N.J. and National Brain Research Centre core funds. P.C. was supported by Council of Scientific and Industrial Research Research Associate Fellowship and Government of India 9/821(0034)/2011-EMR-I. We thank Leslee Lazar, Hisham Mohammed, Niranjan Kambi, Vasav Arora, and Priyabrata Halder for help in electrophysiological and surgical procedures; Mithlesh Singh and Hari Shankar for histological and other support; and Dr. V. Rema for helpful comments on the manuscript. below level of the lesion. Chronic lesions of the dorsal columns in adult primates result in large-scale brain reorganization in multiple somatosensory areas of the brain. This reorganization results in expansion of intact chin inputs into the deafferented hand region of primary somatosensory area $3 \mathrm{~b}$, second somatosensory area S2, parietal ventral area PV (Jain et al., 1997, 1998a; Kaas et al., 2008; Tandon et al., 2009), ventroposterior (VP) nucleus of

Correspondence should be addressed to Dr. Neeraj Jain, National Brain Research Centre, N.H. 8, Nainwal Road Manesar (Haryana), 122 051, India. E-mail: neeraj.jain@nbrc.ac.in or njain.nbrc@gmail.com. DOI:10.1523/JNEUROSCI.2069-15.2015

Copyright $\odot 2015$ the authors $\quad 0270-6474 / 15 / 3513475-12 \$ 15.00 / 0$ 
Table 1. Details of the monkeys and tracer injection sites

\begin{tabular}{|c|c|c|c|c|c|}
\hline Monkey no. & Macaca species & Sex & Weight & Spinal cord lesion, side, and level & Hemisphere and the representation in area $3 b$ injected with the tracer \\
\hline 09-51NM & M. mulatta & Female & $5.1 \mathrm{~kg}$ & Unlesioned & Left hand and face \\
\hline $10-15 N M$ & M. mulatta & Female & $6.0 \mathrm{~kg}$ & Unlesioned & Right hand and face \\
\hline 10-31NM & M. mulatta & Female & $7.0 \mathrm{~kg}$ & Unlesioned & Left hand \\
\hline $11-22 N M$ & M. mulatta & Female & $4.4 \mathrm{~kg}$ & Unlesioned & Left hand \\
\hline LM95 & M. radiata & Male & $11.3 \mathrm{~kg}$ & Left, C4/C5 & Deafferented right hand (expanded chin) \\
\hline LM105 & M. mulatta & Male & $8.8 \mathrm{~kg}$ & Left, C5 & Deafferented right hand (expanded chin) \\
\hline 07-118LM & M. mulatta & Female & $8.9 \mathrm{~kg}$ & Left, C4/C5 & Deafferented right hand (expanded chin) and face \\
\hline LM58 & M. mulatta & Male & $11.4 \mathrm{~kg}$ & Left, C6/C7 & Deafferented right hand (expanded chin) and face \\
\hline LM59 & M. mulatta & Male & $11.3 \mathrm{~kg}$ & Left, $C 5$ & Deafferented right hand (expanded chin) \\
\hline
\end{tabular}

the thalamus (Jones and Pons, 1998; Kaas et al., 1999; Jain et al., 2008), and cuneate nucleus of the brainstem (Kambi et al., 2014). Similar reorganization in area $3 \mathrm{~b}$ is also seen in monkeys with chronic transection of the dorsal roots from C2 to T4 (Pons et al., 1991). Because reorganization is observed at multiple sites along the somatosensory pathway, it has been proposed that reorganization could take place at all these sites independently, or changes at upstream areas could be a reflection of the downstream reorganization (Pons et al., 1991; Kaas et al., 1999; Jones, 2000; Kambi et al., 2014). In the medulla, axonal sprouting has been observed from the spinal trigeminal nucleus into the cuneate nucleus in monkeys with dorsal column lesions (Jain et al., 2000). We have recently shown that reorganization of the brainstem nuclei (i.e., expansion of the chin inputs into the deafferented cuneate nucleus) is the key change that is reflected as expansion of the chin inputs in area $3 \mathrm{~b}$ (Kambi et al., 2014).

Axonal sprouting in the cortex has been reported following limb amputations (Florence et al., 1998), focal retinal lesions (Darian-Smith and Gilbert, 1994), and cortical injuries (Dancause et al., 2005). Therefore, growth of intrinsic corticocortical connections across the hand-face border in area $3 \mathrm{~b}$ could take place in monkeys with chronic dorsal column lesions. Even though it may not be the primary driver of brain plasticity, cortical sprouting can contribute toward robustness of the reorganization and shaping of receptive field properties of neurons. Ascending thalamocortical inputs from the medial subnucleus (VPM) of the ventroposterior nucleus could also sprout into the deafferented hand region of area $3 \mathrm{~b}$ and contribute toward brain reorganization. Therefore, it is important to determine whether such growth takes place to understand consequences of deafferentation in adult brains and mechanisms of plasticity.

Here we determined intrinsic cortical connections between the hand and chin representations in area $3 \mathrm{~b}$ of monkeys
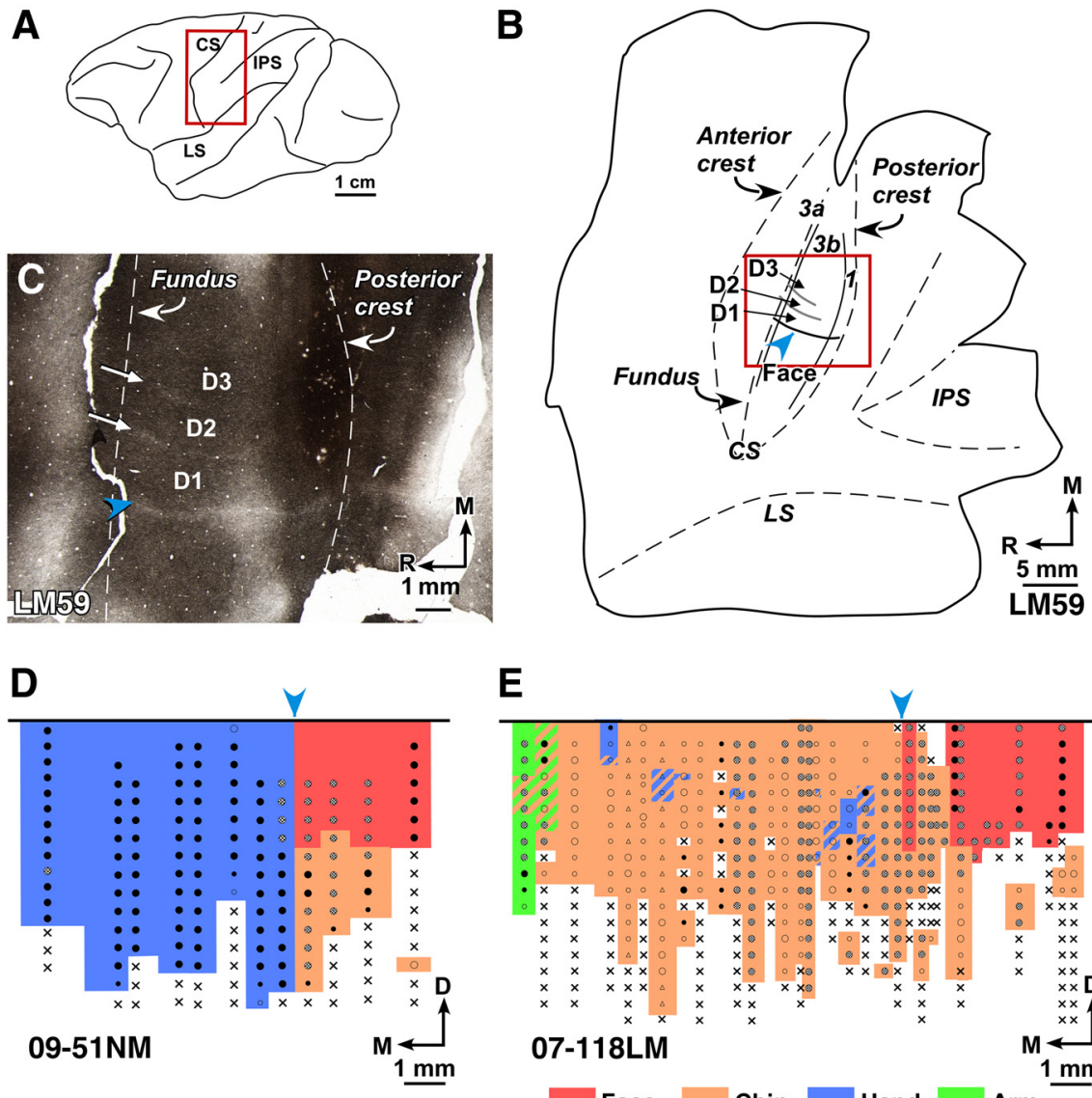

E

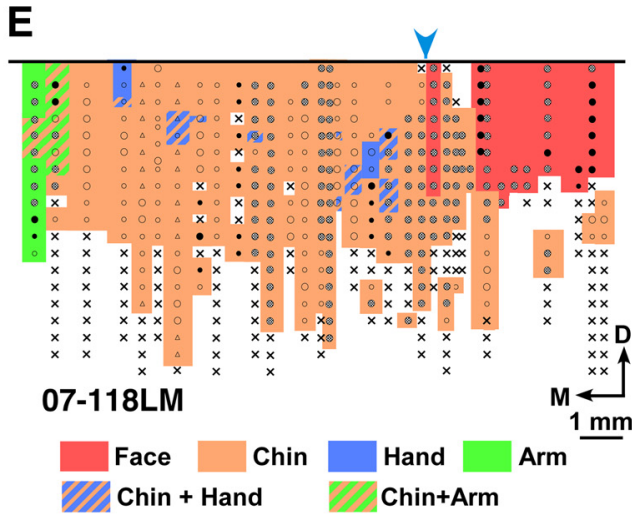

Figure 1. A, Schematic diagram of lateral view of the macaque monkey brain showing location of the central sulcus (CS). Red rectangle represents the approximate region shown as a flattened view of the cortex in $\boldsymbol{B}$. $\boldsymbol{B}$, Drawing of a histological section of the flattened cortex through area $3 \mathrm{~b}$ of Monkey LM59. Dashed lines indicate anterior crest, fundus, and posterior crest of the CS. Solid lines indicate approximate boundaries of area $3 \mathrm{~b}$ in the posterior bank of the $\mathrm{CS}$. Within area $3 \mathrm{~b}$, hand-face septum marking the hand-face border (blue arrowhead), and interdigital borders between D1, D2, and D3 are shown (compare C). Locations of part of the intraparietal sulcus (IPS) and the medial crest of lateral sulcus (LS) are shown for reference. Red rectangle represents the approximate region shown in C. C, Photomicrograph of a myelin-stained section of the flattened cortex of macaque Monkey LM59 with chronic lesion of the spinal cord. Blue arrowhead points to the myelin-light HFS extending rostrocaudally, which separates medial hand and lateral face representation in area $3 \mathrm{~b}$. Straight white arrows indicate the fainter septa between digits D1-D2 and D2-D3. D, Somatotopic map of area 3b of normal Monkey 09-51NM showing representation of the hand (blue), chin (orange), and rest of the face (red). Blue arrowhead indicates location of the hand-face border. Nature of the neuronal response evoked at each recording site is marked with a dot (see legend). Sites at which no responses were evoked are marked with crosses (NR). $\boldsymbol{E}$, Somatotopy in area $3 \mathrm{~b}$ of Monkey $07-118 \mathrm{LM}$ with chronic lesion of dorsal columns of the spinal cord. The chin representation expanded medially into the deafferented hand region. At few sites, neurons responded to tactile stimulation of D1, D3, and arm (green) because there was sparing of some of the dorsal column fibers (Fig. 4). Blue arrowhead indicates the hand-face border estimated in relation to the tip of intraparietal sulcus (see Materials and Methods). Large dots represent brisk neuronal responses. Small dots represent weak responses. Small triangles represent the sites where the response was very weak. 3a, Area 3a; 3b, area $3 b ; 1$, area $1 ; D$, dorsal; $M$, medial; $R$, rostral. 
A

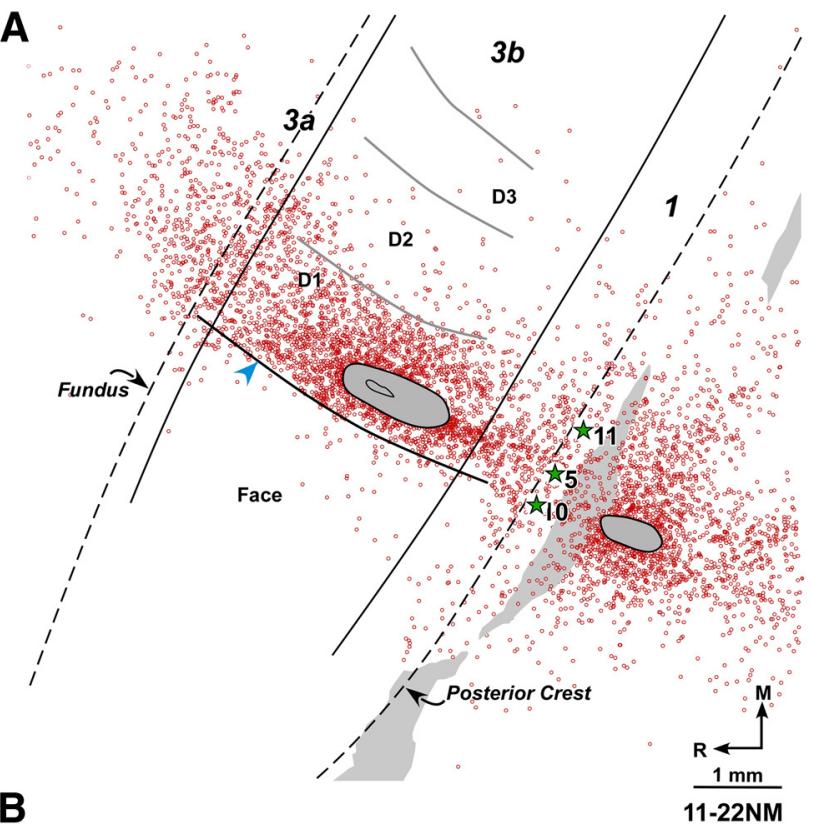

B
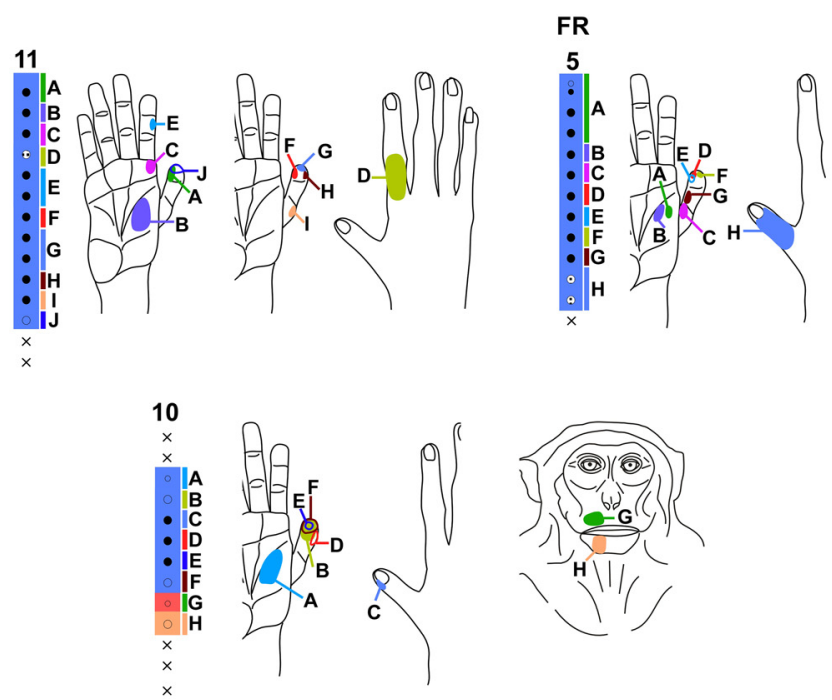

Figure 2. $\quad A$, Composite plot of labeled neurons following injection of FR in D1 representation of normal Monkey 11-22NM shown on drawing of a section of the flattened cortex. Dashed lines indicate fundus and posterior crest of the central sulcus. Solid lines indicate approximate locations of the rostral and caudal borders of area $3 \mathrm{~b}$. Gray ovals outline the region of injection core. Open circles represent FR-labeled neurons. There are only few labeled neurons in the face representation lateral to HFS (blue arrowhead). HFS and the border between digits (gray curved lines) were located from myelin-stained sections. Gray shaded area on the right represents the region that was damaged in few of the sections during tissue processing. Stars indicate approximate locations of the electrode penetration sites for which receptive fields are shown in $\boldsymbol{B}$. $\boldsymbol{B}$, Receptive fields of neurons at and around the FR injection site shown for three adjacent electrode penetration sites. Injection of FR was centered at penetration 5. Receptive fields and responses of neurons at the recording sites marked by uppercase letters are shown by corresponding letters on adjacent figurines of the hand and face. Other conventions same as for Figure 1.

with chronic unilateral lesions of the dorsal columns. Because data from normal macaque monkeys are extremely limited (Manger et al., 1997), we also determined the intrinsic connections in normal monkeys. In addition, thalamocortical connections between the hand and face representations in the ventroposterior nucleus and area $3 \mathrm{~b}$ were determined in monkeys with dorsal column lesions and compared with normal monkeys.
Table 2. Percentage of labeled neurons in the hand and the face representations in normal and lesioned monkeys ${ }^{a}$

\begin{tabular}{lll}
\hline & $\begin{array}{c}\text { Labeled neurons in the } \\
\text { representation in which } \\
\text { tracer was injected (\%) }\end{array}$ & $\begin{array}{l}\text { Neurons labeled across the } \\
\text { hand-face border (\%) }\end{array}$ \\
\hline $\begin{array}{ll}\text { Monkey no. } \\
\text { Normal monkeys, tracer injected } \\
\text { in hand }\end{array}$ & \\
09-51NM & 97.76 & 2.24 \\
10-15NM & 100 & 0 \\
10-31NM & 100 & 0 \\
11-22NM & 96.31 & 3.69 \\
Mean \pm SEM & $98.52 \pm 0.91$ & $1.48 \pm 0.91^{*}$ \\
Lesioned monkeys, tracer & & \\
injected in deafferented hand & & \\
07-118LM & 99.77 & 0.23 \\
LM58 & 99.30 & 0.70 \\
Mean \pm SEM & $99.53 \pm 0.23$ & $0.46 \pm 0.23^{*}$ \\
Normal monkeys, tracer injected & & \\
in face & & 0.52 \\
09-51NM & 99.48 & 0.20 \\
10-15NM & 99.80 & $0.36 \pm 0.16^{* *}$ \\
Mean \pm SEM & $99.64 \pm 0.16$ & \\
Lesioned monkeys, tracer injected & & 0 \\
in face & & 1.92 \\
07-118LM & 100 & $0.96 \pm 0.96^{* *}$ \\
LM58 & 98.08 & \\
Mean \pm SEM & $99.04 \pm 0.96$ & \\
\hline
\end{tabular}

${ }^{a}$ Differences in the number of labeled neurons across the hand-face border between normal and lesioned monkeys were nonsignificant.

${ }^{*} p=0.36$ (Welch's $t$ test); ${ }^{* *} p=0.65$ (Welch's $t$ test).

\section{Materials and Methods}

All animal protocols were approved by the Institutional Animal Ethics Committee of National Brain Research Centre, and Committee for the Purpose of Control and Supervision of Experiments on Animals, Government of India, and conformed to National Institutes of Health guidelines. Five adult macaque monkeys of either sex, with chronic lesions of the dorsal columns (four Macaca mulatta and one Macaca radiata) with $>2$ years of recovery period were used for these experiments (for details, see Table 1). In addition, connections were determined in four monkeys without any lesion (M. mulatta). All monkeys were part of other related experiments (Dutta et al., 2014; Kambi et al., 2014, and other unpublished studies).

Spinal cord lesion. Spinal cord lesions were made as previously described (Kambi et al., 2011). Briefly, the monkeys were anesthetized with a mixture of ketamine $(8 \mathrm{mg} / \mathrm{kg}$, i.m. $)$ and xylazine $(0.4 \mathrm{mg} / \mathrm{kg}$, i.m. $)$ with supplemental doses (one-tenth of the initial dose) as required. Upper back of the monkeys was shaved and prepared for surgery. A midline incision was made at the level of the cervical vertebrae, and the muscles were retracted. A partial laminectomy was performed, and dura was resected to expose the spinal cord. Dorsal columns were transected on the left side using a pair of fine forceps, taking care to minimize damage to the surface blood vessels. After the lesion, dura was folded back in place, and the spinal cord was covered with gel foam. The muscles were sutured in layers using absorbable sutures, and the skin with nonabsorbable sutures (Ethicon, Johnson \& Johnson). The animals were given antibiotics (enrofloxacin; $5 \mathrm{mg} / \mathrm{kg}$, i.m.), analgesics (diclofenac $1.6 \mathrm{mg} / \mathrm{kg}$, i.m.), and dexamethasone (in reducing dosages starting with $2 \mathrm{mg} / \mathrm{kg}$, i.m.) for $5 \mathrm{~d}$ after surgery (Jain et al., 2008). Recovery was uneventful, and no complications were observed.

Multiunit mapping. Somatotopy in the region of the hand and face representations in area $3 \mathrm{~b}$ was determined before injections of neuroanatomical tracers by multiunit mapping performed under surgically sterile conditions using procedures similar to those described previously (Tandon et al., 2009).

Briefly, the animals were anesthetized to surgical levels with a mixture of ketamine and xylazine as described above. The head was fixed in a 

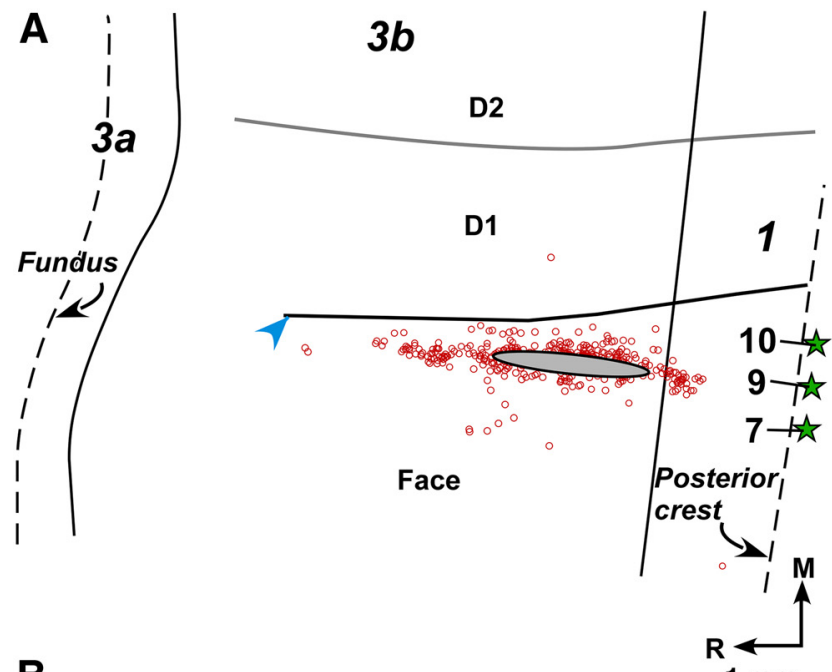

B

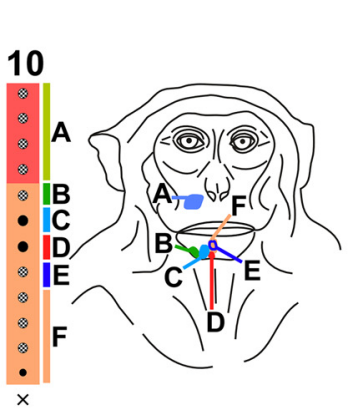

FR

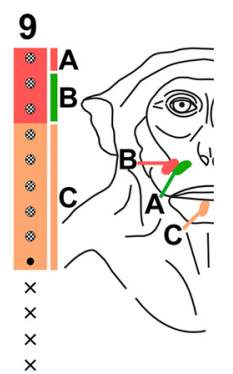

region required taps instead of light touch (Jain et al., 2008). We injected $0.03-0.08 \mu \mathrm{l}$ of Fluororuby (FR; 10,000 MW; 10\% in distilled water; Invitrogen), Fluoroemerald (FE; 10,000 MW; $10 \%$ in distilled water; Invitrogen), or biotinylated dextran amine (BDA; a mixture of $10 \%$ $10,000 \mathrm{MW}$ and $3 \% 3000 \mathrm{MW}$ BDA in $0.01 \mathrm{M}$ sodium phosphate buffer). $\mathrm{FR}$ and $\mathrm{FE}$ were pressure injected using a glass micropipette attached to a Hamilton syringe, whereas BDA was injected iontophoretically ( $5 \mu \mathrm{A}$ positive current, $7 \mathrm{~s}$ on and $7 \mathrm{~s}$ off pulses, total time $15 \mathrm{~min}$ ). In one lesioned monkey (LM59), large multiple injections of wheat germ agglutinin conjugated to horseradish peroxidase (WGA-HRP; $\%$ in sterile water) were made to fill the entire hand representation. Injections of WGA-HRP were made at depths of 3000, 4000, and $5000 \mu \mathrm{m}$ at each of the three penetration sites. In all monkeys, connections of the right hemisphere were determined, except Monkeys 09-51NM, 10-31NM, and 11-22NM in which left hemisphere was injected. In four monkeys (0951NM, 10-15NM, 07-118LM, and LM58), two injections (one in the hand and one in the face representation) were made. After injections were made, the brain was covered with sterile contact lenses (Johnson \& Johnson), and the dura was folded back. A piece of sterile gel foam was placed on top of the dura, and the craniotomy was sealed with a cap made from dental cement. The muscle and the skin were sutured in place. Animals were monitored closely during the recovery period. They were given enrofloxacin, dexamethasone, and diclofenac as described above.

Detailed mapping and histology. Two to seven days after injections of tracers, a detailed somatotopic map of area $3 \mathrm{~b}$ (Fig. 1) was obtained for all

A

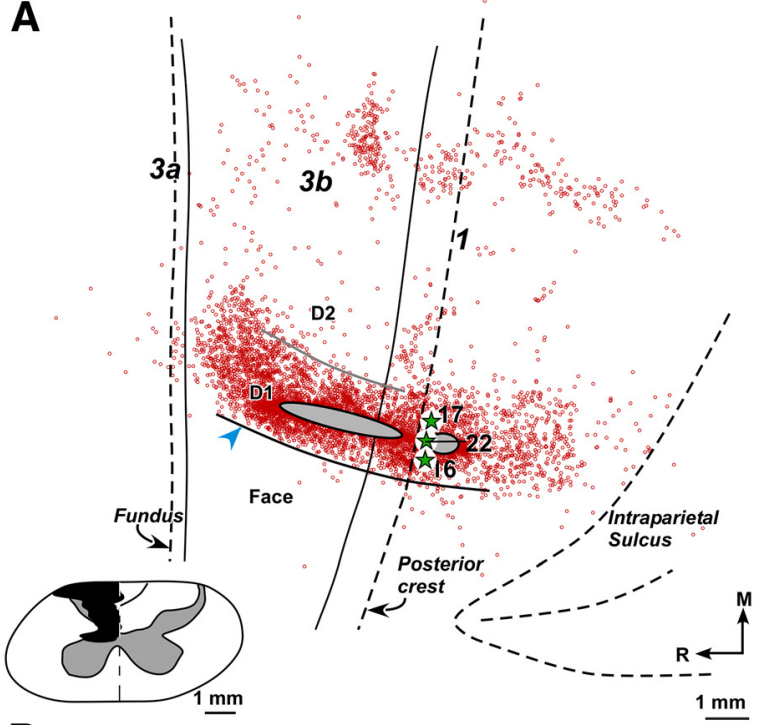

B

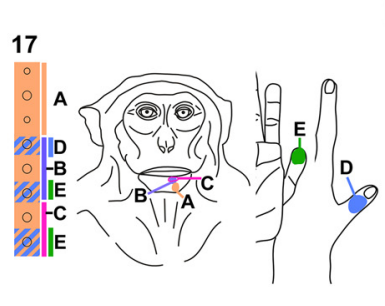

FR
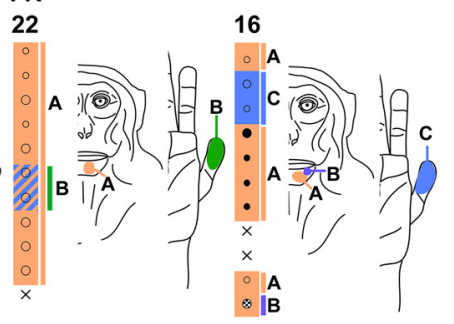

Figure 4. A, Composite plot of labeled neurons after injection of FR in the deafferented hand representation of Monkey 07-118LM with chronic spinal cord lesion. HFS and interdigital border were located from myelin-stained sections. Inset, Reconstruction of the spinal cord in a coronal plane showing extent of the lesion (black). Boundaries of gray matter and the midline (dashed line) are marked. Border between cuneate and gracile tracts on intact right side drawn from the spinal cord sections is also shown. $\boldsymbol{B}$, Receptive fields of neurons at and around the FR injection site shown for three adjacent electrode penetration sites. Injection of FR was centered at penetration 22. Although the injection site was medial to HFS, the neurons responded to touch on the chin due to the reorganization. At few sites, neurons had responses to touch on the hand because the lesion was not complete. Other conventions same as for Figure 2. 


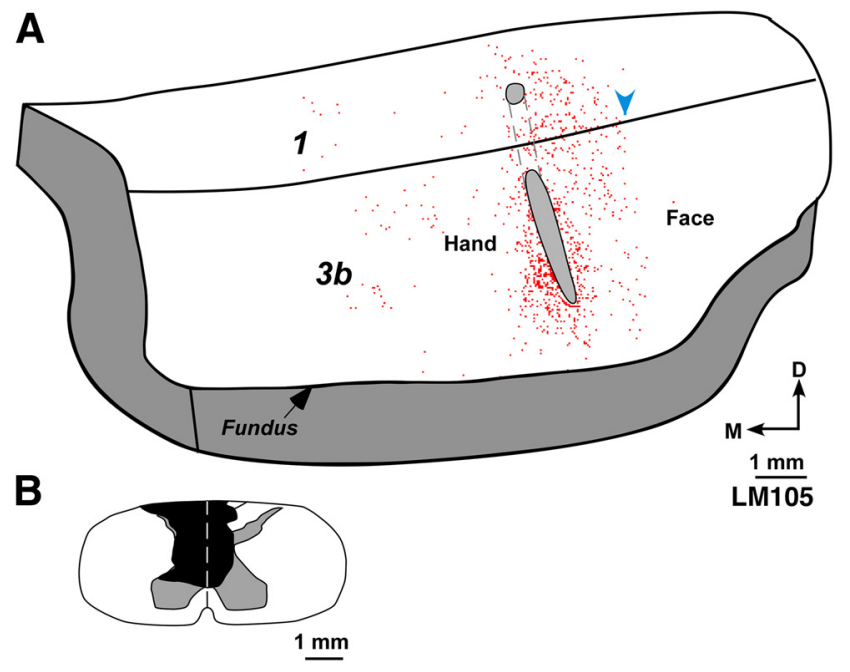

Figure 5. A, A3D reconstruction of posterior bank of the central sulcus showing enface view of area $3 \mathrm{~b}$ of lesioned Monkey LM105. This view was reconstructed from drawings of parasagittal sections (see Materials and Methods). Outline of the injection core of FR injected in deafferented hand representation is shown (gray ovals). Locations of the labeled neurons (red dots) are marked. Labeled neurons were not present across the hand-face border (blue arrowhead). $B$, Reconstruction of the spinal cord in a coronal plane showing the extent of the lesion (black). Other conventions same as for Figures 2 and 4.

the monkeys, except for LM58 and 11-22NM, using methods described above. The monkeys were killed with a lethal dose of pentobarbital (17.5 $\mathrm{mg} / \mathrm{kg}$, i.v. $)$ and perfused transcardially with $\mathrm{PBS}(0.9 \% \mathrm{NaCl}$ in phosphate buffer, $0.1 \mathrm{M}$; $\mathrm{pH} 7.4$ ), followed by $2 \% \mathrm{PFA}$, and then by $2 \%$ PFA in $10 \%$ sucrose, except for Monkeys LM95 and LM105. These two monkeys were perfused with $3 \%$ PFA because the cortex was not flattened. Cortex was not flattened in these two monkeys because these monkeys were also part of other experiments where it was necessary to cut the cortex in a conventional plane for data analysis.

For flattening, the cortex was separated from the underlying tissue, and a block of cortex in the region of the central sulcus was manually flattened by opening the sulci (Jain et al., 2008), photographed, and cryoprotected overnight in $30 \%$ sucrose between glass slides. The flattened cortex was frozen and cut parallel to the cortical surface on a sliding microtome into $40-\mu \mathrm{m}$-thick sections. Series of alternate sections were either mounted unstained to visualize fluorescently labeled neurons or processed for BDA (Reiner et al., 2000) or HRP (Gibson et al., 1984) visualization. Other series of sections were stained for myelin using a modified Gallyas procedure (Jain et al., 1998b) to visualize the hand-face border in area $3 \mathrm{~b}$, which is visible as hand-face septum (HFS) (Fig. 1) (Jain et al., 2008). For Monkeys LM95 and LM105, the cortex was cut in an off-parasagittal plane, approximately perpendicular to the central sulcus, in $60-\mu \mathrm{m}$-thick sections. In these monkeys, a series of every fifth section was mounted unstained for visualization of fluorescently labeled neurons. Other series of sections were stained for cytochrome oxidase (CO) (Wong-Riley, 1979), Nissl substance and AChE (Mohammed and Jain, 2014).

The thalamus was cryoprotected as above and cut in a coronal plane into $50-\mu \mathrm{m}$-thick sections. A series of thalamic sections were processed for fluorescence, BDA, or HRP as described above. Other series of the thalamic sections were stained for $\mathrm{CO}$ or Nissl substance to visualize the nuclear boundaries.

Spinal cord from the lesioned monkeys was removed and cryoprotected as above. The spinal cord was cut into $50-\mu \mathrm{m}$-thick sections in a horizontal plane.

Reconstruction of the spinal cord lesion. Horizontal sections of the spinal cord were used to reconstruct the spinal cord in a coronal plane. Drawings of the spinal cord sections in the region of the lesion were made using a microscope equipped with camera lucida. The maximal extent of the lesion and boundaries of the gray and white matter were measured for each drawing and plotted on the graph
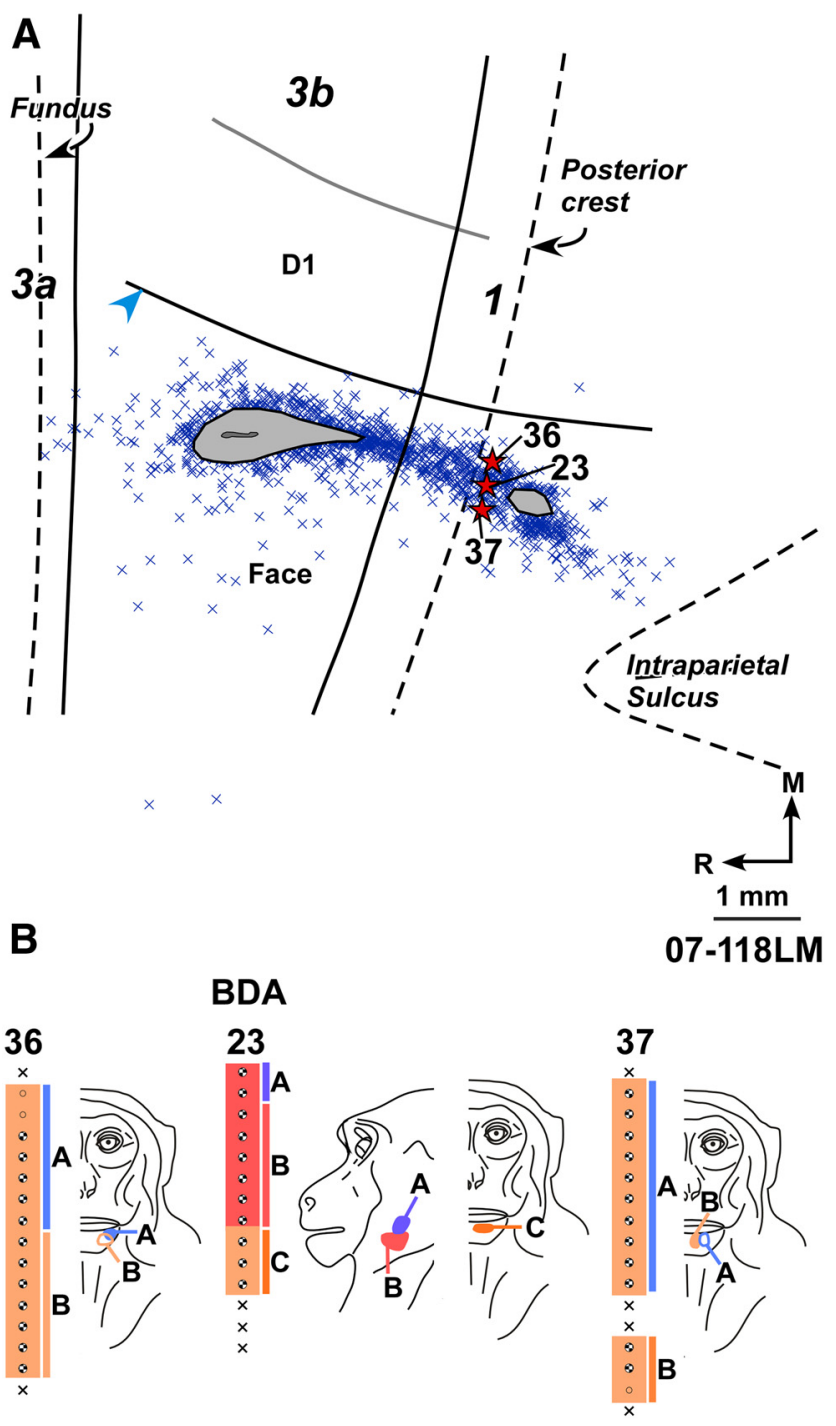

Figure 6. $A$, Composite plot of labeled neurons after injection of BDA in the normal chin and lateral jaw representations of Monkey 07-118LM with chronic spinal cord lesion. HFS and the interdigital border were located from myelin-stained sections. $\boldsymbol{B}$, Receptive fields of neurons at and around the BDA injection site shown for three adjacent electrode penetration sites. Injection of BDA was centered at penetration 23. For extent of the lesion, see Figure 4. Other conventions same as for Figures 2 and 4.

paper to reconstruct the spinal cord and extent of the lesion (Kambi et al., 2014).

Data analysis. Locations of the labeled neurons were plotted using Neurolucida software (Microbrightfield) coupled to a computercontrolled microscopic stage with direct visualization through the eye piece as described previously (Mohammed and Jain, 2014). Outlines of the sections and locations of blood vessels and other tissue artifacts were plotted to help align different sections. Adjacent sections, stained for myelin, were drawn at the same magnification, and myeloarchitectonic features and HFS were marked (Jain et al., 1998b). Sections with plots of labeled neurons and drawings from the myelin-stained sections were overlapped using Canvas X software (ACD Systems) to ascertain locations of the labeled neurons. Only neurons determined to be in area $3 \mathrm{~b}$ were considered for quantitative analysis.

Boundaries of area $3 \mathrm{~b}$ in flattened sections were drawn using myelinstained sections, if visible. In addition, we analyzed parasagittal brain sections from three monkeys that were available in the laboratory from other experiments, and stained for Nissl substance, AChE, or CO to determine distance of area $3 \mathrm{~b}$ borders from the lip and the fundus of the central sulcus. Average distance in the region of the hand and face rep- 

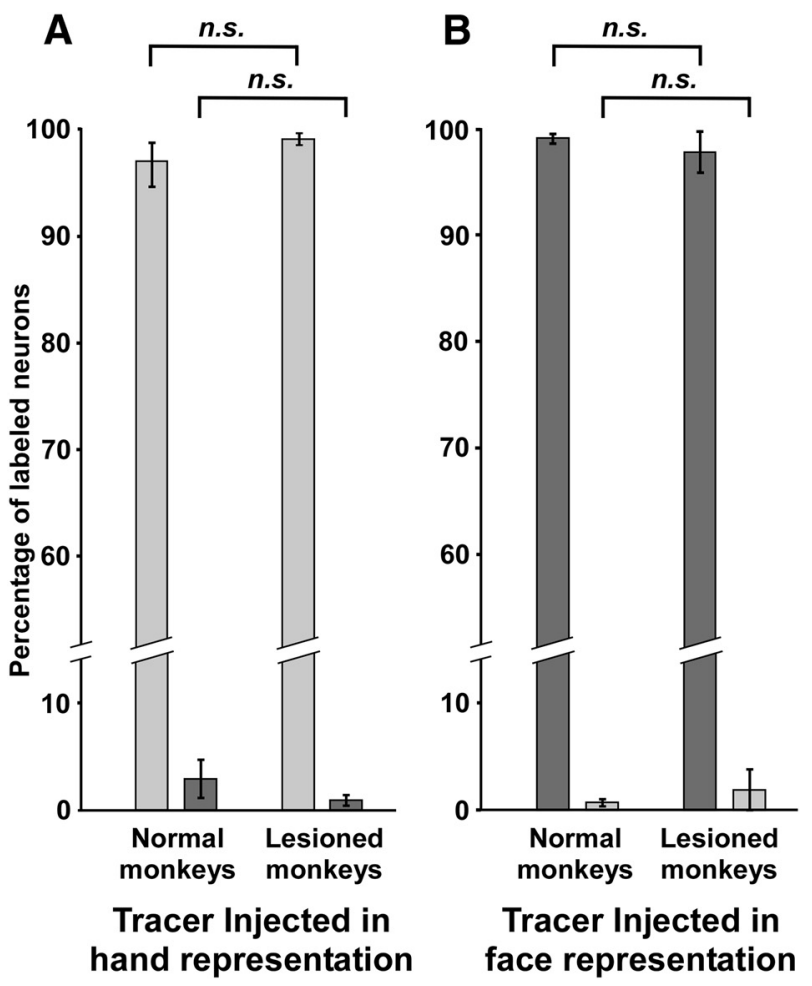

Labeled neurons in hand

$\square$ Labeled neurons in face

Figure 7. $\quad \boldsymbol{A}$, Bar graph showing percentage ( \pm SEM) of labeled neurons in the hand and the face representations following injections of neuroanatomical tracers in the hand representation of normal and lesioned monkeys. $\boldsymbol{B}$, Bar graph showing percentage ( \pm SEM) of labeled neurons in the face and the hand representations following injections of neuroanatomical tracers in the face representation of normal and lesioned monkeys. n.s., Nonsignificant difference (see Results).

resentations was found to be $1.53 \mathrm{~mm}$ from the lip of the sulcus and 0.50 $\mathrm{mm}$ from the fundus. These distances were marked on drawings of the sections. Finally, the electrophysiological map was overlaid on drawings of the cell plots in Canvas software. The number of labeled neurons in the hand representation and the chin representation in area $3 \mathrm{~b}$ was determined. Statistical analysis was done using GraphPad Prism software (GraphPad Software). Only data from monkeys in which the cortex was flattened were considered for statistical analysis because location of the hand-face border was precisely determined in these monkeys. Locations of neurons in areas S2 and PV were also plotted if these areas were present in the block of the cortex that was flattened. The presence of labeled neurons in these areas confirmed that the amount of tracer injected and the transport times were adequate to reveal even long-distance corticocortical connections.

Sections stained for HRP were visualized under both dark-field and bright-field illuminations using a microscope equipped with a drawing tube at $10 \times$ magnification, and the outline of regions containing labeled terminal and neurons was marked. Higher magnification was used as required to verify presence of label in the neurons.

Labeled neurons in sections of the brain that were sectioned in off-parasagittal plane were plotted, and drawings of the sections were assembled in a $3 \mathrm{D}$ reconstruction of the posterior bank of the central sulcus using Neurolucida software. Here, location of the hand-face border was determined from the electrophysiological map as well as anatomically, to be located near the tip of the intraparietal sulcus (Jain et al., 2008).

Retrogradely labeled neurons in the thalamic sections were plotted as described above to determine the sources of thalamic inputs to the hand and face representations.

\section{Results}

We first present results describing intrinsic connections of the hand and face representations in the region of hand-face border in area $3 \mathrm{~b}$ of unlesioned monkeys, followed by those in monkeys with lesions of the dorsal columns. Finally, we describe thalamocortical connections in moneys with lesions and compare them with normal monkeys.

Intrinsic connections of the hand in normal monkeys Injections of FE in Monkey 10-15NM, BDA in Monkeys 0951NM and 10-31NM, and FR in Monkey 11-22NM (Fig. 2) were made in D1 (digit 1) representations in area $3 \mathrm{~b}$, close to the hand-face border. In Monkeys 10-31NM and 11-22NM, core of the injection site had minor involvement of the palm representation (Fig. 2). In Monkey 11-22NM, there was a small patch of injection core located dorsally in area 1 (Fig. $2 A$ ). In all these cases, the cortex was flattened and a series of alternate sections was stained for myelin to reveal the HFS (Jain et al., 1998b), which confirmed that the injection core did not cross the handface border. Least distance between the lateral edge of the injection core and HFS ranged from 230 to $800 \mu \mathrm{m}$.

The results were similar in all four monkeys. Large numbers of labeled neurons were seen in the hand region around the injection site. Labeled neurons were also seen in adjacent area 1 , and few neurons were present in area 3a. No neurons across HFS in area $3 \mathrm{~b}$ were present in Monkeys 10-15 and 10-31NM. However, in two of the monkeys (11-22NM and 09-51NM), labeled neurons were present in the face representation. In Monkey 11$22 \mathrm{NM}$ (Fig. 2A), labeled neurons in area $3 \mathrm{~b}$ face representation were $3.69 \%$ of the total $(n=2197)$ area 3 b neurons (Table 2$)$; and in Monkey 09-51NM, the percentage was $2.24 \%(n=625)$. Most of the labeled neurons in the face region were present within 250 $\mu \mathrm{m}$ of the HFS, although few scattered neurons were observed up to $1250 \mu \mathrm{m}$.

\section{Intrinsic connections of the face in normal monkeys}

Injection of FR was made in the face representation in Monkey 09-51NM (Fig. 3) and BDA in Monkey 10-15NM. In Monkey 09-51NM, the injection site encompassed the chin and snout representations (Fig. 3B). In Monkey 10-15NM, the injection site was more superficial in the sulcus, in the region of snout and cheek representations, although the deep part of the injection core likely involved chin representation. The injection core was confined to area $3 \mathrm{~b}$ in both these monkeys, although it touched area 3b-1 border in Monkey 10-15NM. Minimum distance of the injection core from HFS was $260 \mu \mathrm{m}$ in Monkey 09-51NM (Fig. $3 A$ ) and $500 \mu \mathrm{m}$ in Monkey 10-15NM. In both monkeys, $<1 \%$ (Table 2) of the labeled neurons in area $3 \mathrm{~b}$ were found across HFS in the hand region ( $n=194$ for Monkey 09-51NM, 985 for Monkey 10-15NM). Thus, neurons projecting to the face representation in area $3 \mathrm{~b}$ are rare in the hand representation.

Intrinsic connections of the hand region in lesioned monkeys Injections of FR were made in the hand region near the hand-face border in three monkeys (07-118LM, LM105, and LM95) and FE in one monkey (LM58). In addition, in one monkey (LM59), large injections of WGA-HRP were made to fill the entire hand region to reveal even minor connections across the hand-face border, if any. In three monkeys (07-118LM, LM58, and LM59), the cortex was flattened, and location of the hand-face border was determined in myelin-stained sections. In the two remaining monkeys (LM105 and LM95), the cortex was not flattened be- 
A
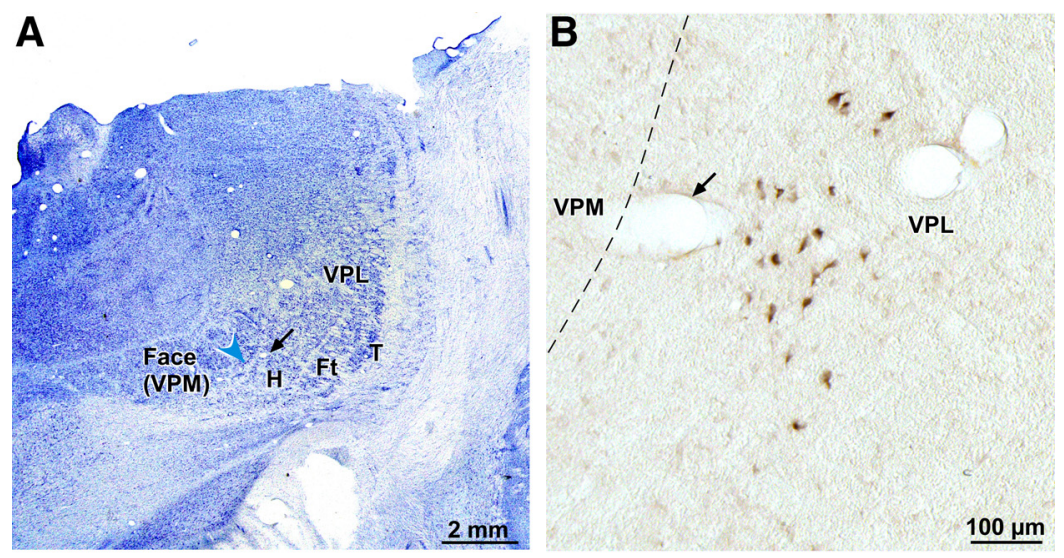

C
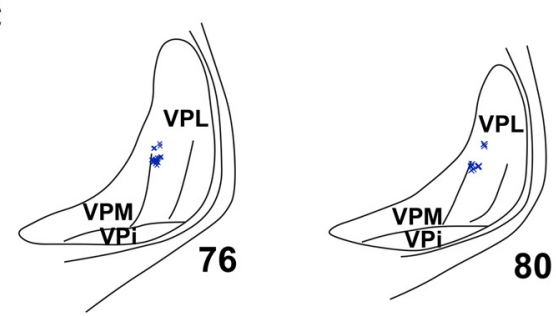

D

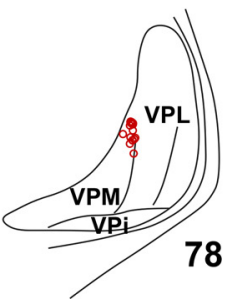

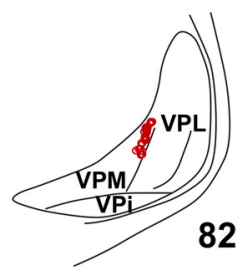

82

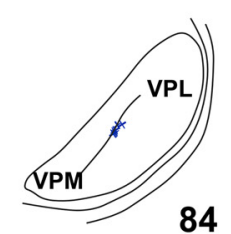

84

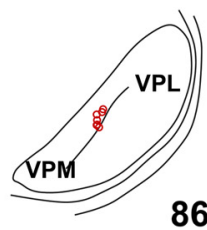

86

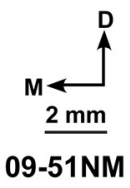

Figure 8. A, Photomicrograph of a Nissl-stained coronal section of the thalamus through ventroposterior (VP) nucleus of Monkey 09-51NM. Medial face subnucleus (VPM) is separated from the lateral subnucleus (VPL) by the arcuate lamina (blue arrowhead). Discrete regions of VPL receive inputs from the hand $(\mathrm{H})$, foot $(\mathrm{Ft})$, tail $(\mathrm{T})$, and other body parts. A faint cell sparse septum separating the hand and the foot region is also obvious. $B, A$ high-power photomicrograph of the adjacent thalamic section showing neurons that were retrogradely labeled following injection of BDA in D1 representation in area $3 \mathrm{~b}$. $\boldsymbol{A}, \boldsymbol{B}$, Corresponding blood vessels are marked with arrows. $C$, Locations of labeled neurons in VPL shown on drawings of three representative rostral to caudal thalamic sections following injections of BDA in D1 representation. The section numbers are marked. $\boldsymbol{D}$, Locations of labeled neurons in VPM in three representative thalamic sections following injections of FR in chin representation. VPi, Ventroposterior inferior subnucleus; D, dorsal; M, medial. D, Orientation arrows also apply to other panels.

cause they were also part of other experiments; therefore, position of the hand-face border was placed near the tip of the intraparietal sulcus (Jain et al., 2008) and estimated from the somatotopic map. In all these monkeys, as for the normal monkeys, intrinsically labeled neurons in area $3 \mathrm{~b}$ were confined to regions around the injection site.

In Monkey 07-118LM, because the spinal cord lesion spared a small region of the dorsal columns (Fig. 4), responses to stimulation of parts of D1 and D3 (digit 3) were observed at few recording sites in area $3 \mathrm{~b}($ Fig. $1 E)$. The injection was centered at a location where neurons had receptive fields on the medial chin and distal D1 (Fig. 4B). The closest distance of lateral edge of the injection core was $700 \mu \mathrm{m}$ from HFS. Although the injection was quite large, most of the labeled neurons were confined to the vicinity of injection core as for the normal monkeys. Medially neurons were found scattered in the region where hand representation is expected. In area 3b, of a total of 2982 labeled neurons, only 7 neurons (i.e., $0.23 \%$ ) were found across HFS (Table 2 ). A small region of injection core was present in area 1.

In Monkey LM58, the lesion was partial. There was sparing of the medial part of fasciculus cuneatus and nearly complete sparing of the fasciculus gracilis. At the injection site, neurons responded to stimulation of the medial chin, distal D1, proximal D2 (digit 2), and distal D2. The closest distance of the injection core from HFS was $1600 \mu \mathrm{m}$. Data showed that, in this monkey, also most of the labeled neurons were in the region around the injection core, with few neurons scattered medially in the expected hand representation. Only few neurons $(0.70 \% ; n=1291)$ were present across HFS in the face representation near the border (Table 2).

In two monkeys (LM95 and LM105) in which the brain was cut in a parasagittal plane, injections of FR were made 2.24 $\mathrm{mm}$ and $2.05 \mathrm{~mm}$ medial to the physiologically determined hand-face border. In both these monkeys, the dorsal column lesion was nearly complete and neurons at only few recording sites responded to touch on the hand. In the deafferented hand region, neurons responded to tactile stimulation of the chin. The FR injections were centered at locations where neurons responded to tactile stimulation of the chin. Superficially, responses to stimulation of the hand were also present at these sites. In these monkeys, no neurons were seen across the hand-face border (Fig. 5A).

In one monkey (LM59) in which large multiple injections of WGA-HRP were made, core of the lateral-most injection was $500 \mu \mathrm{m}$ from HFS, except at the caudal-most location where it was touching HFS (see Fig. 10A). In this monkey, the lesion was nearly complete (see Fig. $10 E)$. At one of the recording sites, response to touch on thenar pad of the palm was present. At all other recording sites, neurons in the hand region responded to touch on the chin (Kambi et al., 2014, somatotopic map of their Fig. 6B). At medial-most locations, neurons responded to touch on the arm as expected (Jain et al., 2008). Observations of the transported label showed results similar to those from monkeys in which FR or FE was injected. We did not find any neurons across HFS despite the large multiple injections.

Comparison of percentage of neurons labeled in the face representation following injections in the hand region between normal monkeys and monkeys with lesions of the dorsal columns showed no significant difference ( $p=0.36$, Welch's $t$ test; Table 2; see Fig. 7).

\section{Intrinsic connections of the face representation in lesioned monkeys}

In two monkeys with spinal cord lesions (Monkeys 07-118LM and LM58), injections of BDA and FR, respectively, were made in the normal chin representation, lateral to the hand-face border. In Monkey 07-118LM (Fig. 6), the closest distance of the injection core was $620 \mu \mathrm{m}$ from HFS. The injection was centered on the region where dorsally neurons responded to tactile stimulation of the lateral jaw and ventrally to the medial chin. A small 
part of the injection core was present in area 1 . Plots of retrogradely labeled neurons showed that no neuron was present medial to HFS in area $3 \mathrm{~b}$.

In Monkey LM58, the closed distance of the injection core was $1.33 \mathrm{~mm}$ from HFS, centered at a site where dorsally neurons responded to stimulation of the upper and lower lips, and ventrally to the medial chin. Despite a large injection, only few scattered neurons were observed medial to HFS, which constituted 1.92\% ( $n=2598)$ of the total neurons labeled in area $3 \mathrm{~b}$.

There was no significant difference between the percentage of neurons labeled across HFS following injections in the face region in normal and the lesioned monkeys ( $p=0.65$, Welch's $t$ test; Table 2 ; Fig. 7).

Thus, our data show that chronic lesion of the dorsal columns and subsequent expansion of the chin representation into the hand region is not accompanied with increase in intrinsic connections between the hand and the chin representations.

\section{Thalamocortical connections}

In normal monkeys, thalamocortical connections were plotted following injections of BDA in D1 representation in Monkeys 09-51NM and 10-31NM, FR in D1 representation in Monkey 11-22NM, and FR in chin representation in Monkey 09-51NM. Plots of retrogradely labeled neurons in VP nucleus of monkeys with injection of neuroanatomical tracer in D1 showed that neurons were confined to the medial-most region of the hand subnucleus of ventral posterior lateral nucleus (VPL), along the lamina between the VPL and VPM (Fig. 8A-C for Monkey 09$51 \mathrm{NM}$ ). Neurons labeled following injections in the chin representation were in the lateral-most part of VPM (Fig. 8D). Normal thalamocortical connections and the somatotopy in the VP nucleus of thalamus have been described by many laboratories, and our data conform to previous reports (Jones and Friedman, 1982; Darian-Smith et al., 1990; Krubitzer and Kaas, 1992; Padberg et al., 2009; Cerkevich et al., 2013).

Thalamocortical connections of the deafferented hand representation were determined in four monkeys with dorsal column lesions. Labeled neurons were plotted following injections of FR immediately medial to HFS in Monkeys 07-118LM and LM105 and FE in Monkey LM58. As described above, neurons at these locations responded to tactile stimulation of the chin because of the cortical reorganization. In all these cases, as for the normal animals, the labeled neurons were located in the medial-most part of the hand subnucleus of VPL, immediately adjacent to the lamina separating VPL and VPM (Fig. 9 for Monkey 07-118LM). In Monkey LM59 where the entire hand representation was filled with WGA-HRP by multiple injections, retrogradely labeled neurons were present in the entire hand subnucleus of VPL (Fig. 10). No labeled neurons in any of these monkeys were present in VPM.

Thalamocortical connections of the normal chin representation in lesioned monkeys were analyzed following injection of BDA in Monkey 07-118LM and FR in Monkey LM58. In both
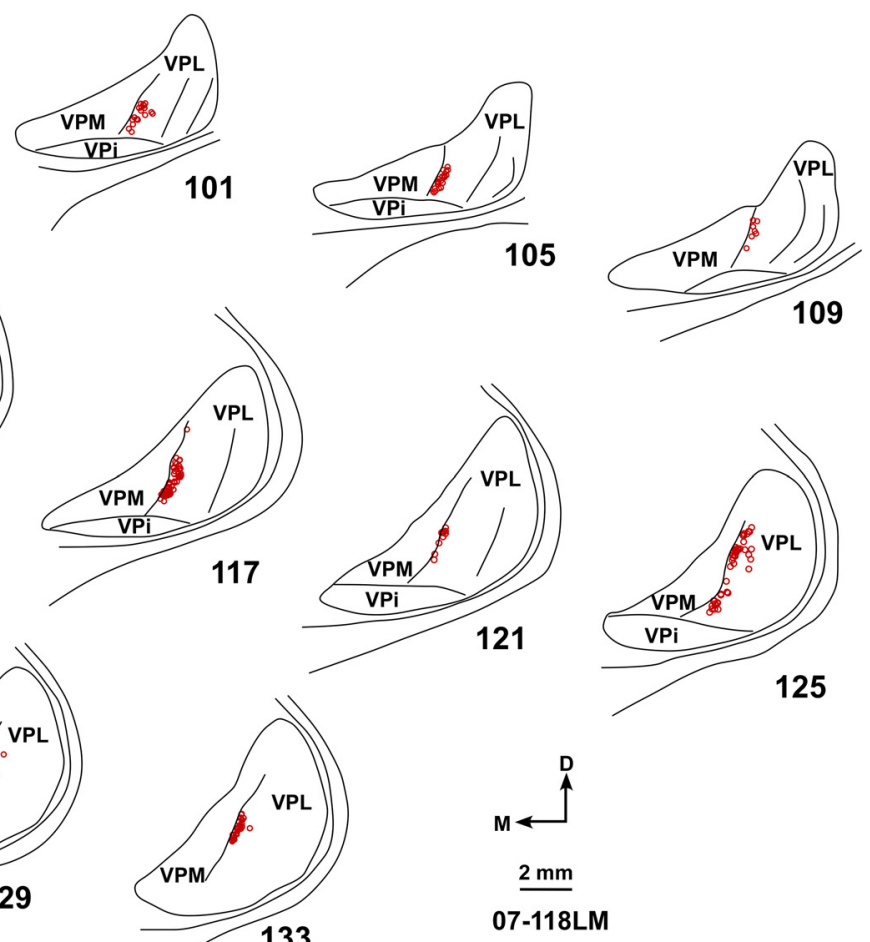

133

07-118LM

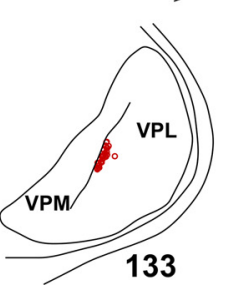

25 these monkeys, retrogradely labeled neurons were present in VPM, along the lamina separating the VPM and VPL (Fig. 11 for Monkey 07-118LM), as for the normal monkeys.

These data show that, following injections of neuroanatomical tracers in the hand or chin representations in area $3 \mathrm{~b}$ in the vicinity of hand-face border, topographical locations of retrogradely labeled neurons in the VP nucleus of monkeys with dorsal columns lesions and extensive cortical reorganization remain the same as in normal monkeys. Thus, no sprouting of thalamocortical axons projecting from the VP nucleus to area $3 \mathrm{~b}$ takes place following chronic lesions of the dorsal columns.

\section{Discussion}

Main findings of this study are as follows: (1) in normal area 3b of macaque monkeys, intrinsic connections across the hand-face border are few, which are confined to the immediate vicinity of the border; (2) in monkeys with long-term unilateral lesions of the dorsal columns at cervical levels, intracortical intrinsic connections do not sprout across the hand-face border; and (3) in the lesioned monkeys, thalamocortical projections of the hand and the face representations in VP nucleus retain their fidelity to the hand and face representations in area $3 \mathrm{~b}$. The connections remain unaltered despite deafferentation of the main driving inputs from the hand to VPL and area $3 \mathrm{~b}$, and large-scale expansion of chin representation into the hand region of both area $3 \mathrm{~b}$ and VPL (Jain et al., 2008; Tandon et al., 2009; Kambi et al., 2014).

\section{Intrinsic connections in area $3 \mathrm{~b}$ of monkeys}

In normal monkeys, we did not find extensive intrinsic connections across the hand-face border. The hand-face border, which is easily seen in histological sections as myelin-light septa in different species of monkeys (Jain et al., 1998b; Iyengar et al., 2007), 

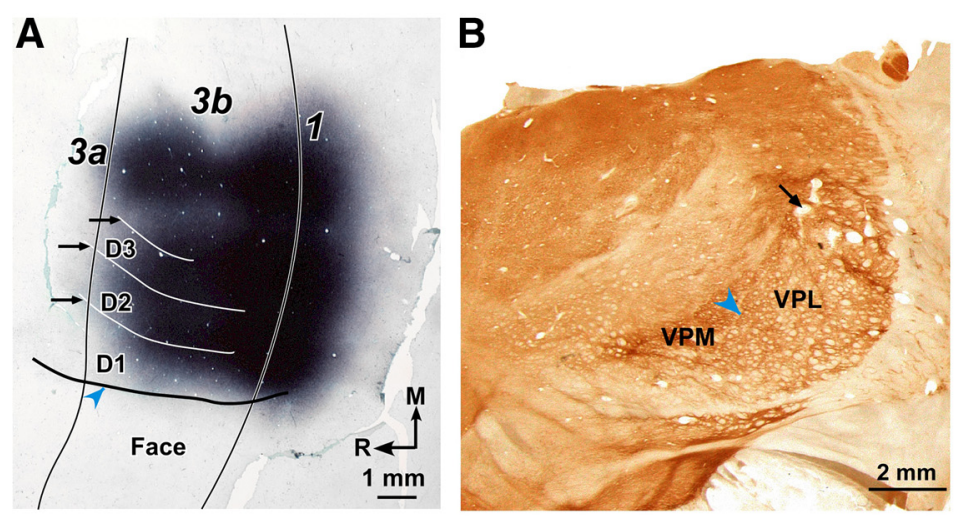

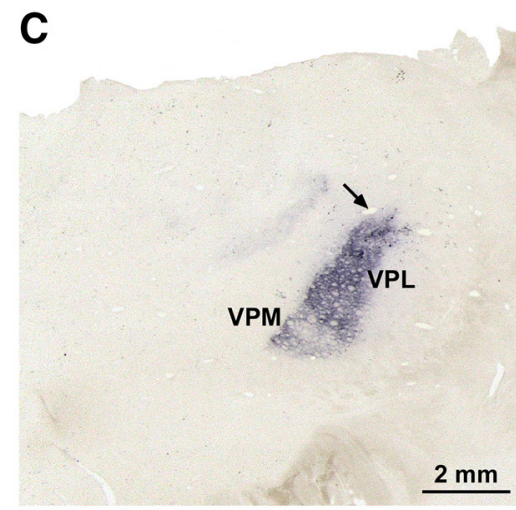

E
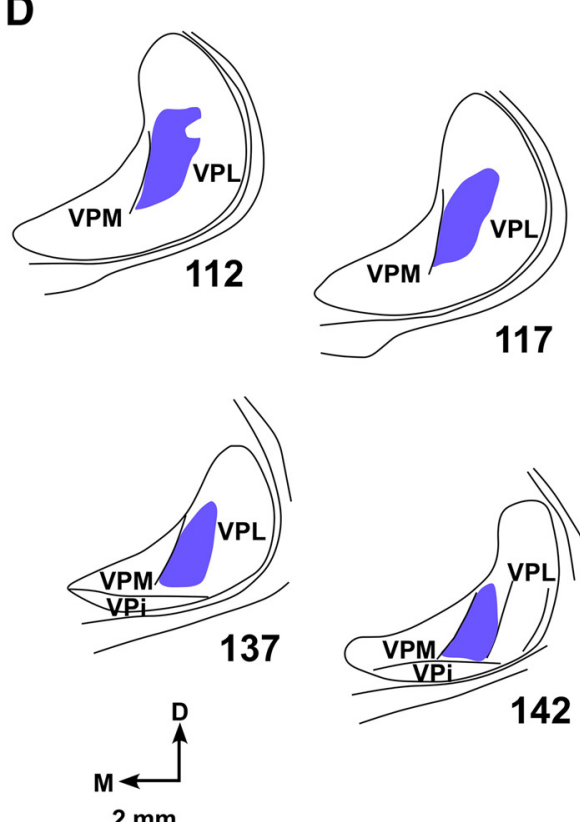

37

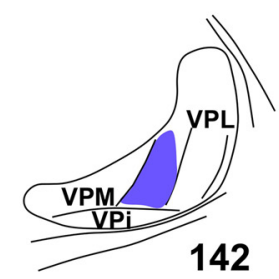

142

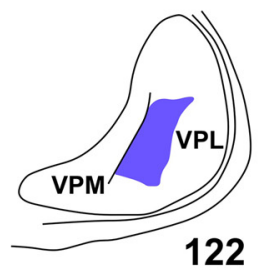

122

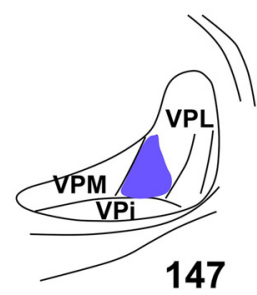

147
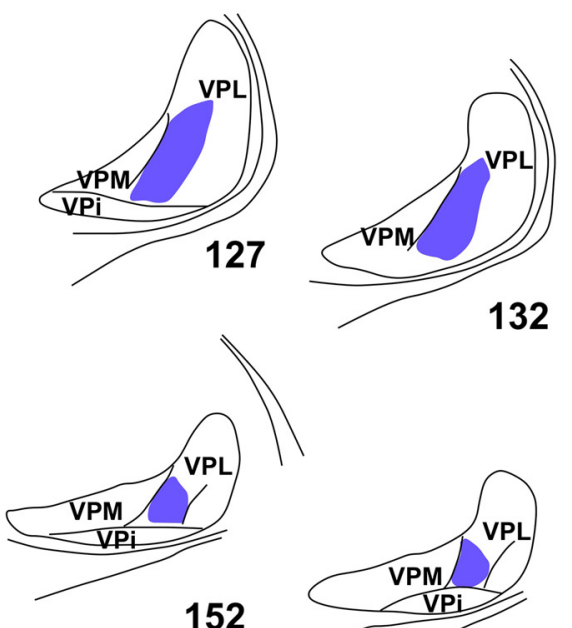

152

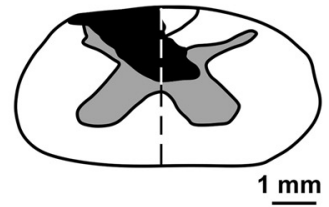

LM59

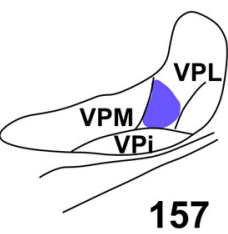

Figure 10. Location of the WGA-HRP label in area $3 \mathrm{~b}$ and VP nucleus following large, multiple injections of the tracer made to fill the entire deafferented hand region of area $3 \mathrm{~b}$ of lesioned Monkey LM59. A, Photomicrograph of a section of the flattened cortex through area $3 \mathrm{~b}$. Solid vertical lines indicate the rostral and caudal boundaries of area $3 \mathrm{~b}$. Blue arrowhead indicates HFS. White horizontal lines (black arrows) indicate the interdigital borders. Note the lack of transported WGA-HRP across the hand-face border. B, Photomicrograph of a cytochrome oxidase-stained coronal section of the thalamus through ventroposterior (VP) nucleus. VPM and VPL are labeled, and the arcuate lamina (blue arrowhead) is marked. C, A photomicrograph of the adjacent thalamic section (section number 132 in $\boldsymbol{D}$ ) showing the transported label. $\boldsymbol{B}, \boldsymbol{C}$, Corresponding blood vessels are marked with arrows. $\boldsymbol{D}$, Location of the transported WGA-HRP in VPL shown in drawings of a series of rostral to caudal thalamic sections. The label is confined to the hand subnucleus of VPL. $E$, Reconstruction of the spinal cord in a coronal plane showing extent of the lesion (black). Orientation arrows shown in $\boldsymbol{D}$ also apply to $\boldsymbol{B}$ and $\boldsymbol{C}$. Other conventions same as for Figures 2, 4, and 8.

likely forms a limiting boundary for information exchange between regions receiving nonadjacent peripheral inputs from hand and face. In area $3 \mathrm{~b}$ of New World monkeys (marmosets, owl monkeys, and squirrel monkeys), also there are only few intrinsic connections that cross the hand-face border (Fang et al., 2002). In this study, connections of the upper lip and hand representations were determined. The Jones laboratory has examined connectivity across the hand-face border in macaque monkeys (Manger et al., 1997). They found an overlap of intrinsic connections between D1 representation and the caudal part of lower jaw/neck representation, but not between D1 and upper lip representation. We extend these observations and show that chin representation also has only few connections across the handface border, which is important because it is the chin representation that expands as a result of massive deafferentations (Pons et al., 1991; Jain et al., 1997, 2008). In studies where intrinsic con- nections of the hand representation in area $3 \mathrm{~b}$ were determined without explicit goal of determining connections across the hand-face border (Burton and Fabri, 1995; Liao et al., 2013; Négyessy et al., 2013), the lateral extent of labeled neurons shows a sharp boundary corresponding to the expected location of the hand-face border. An advantage of the present study is that we have directly compared location of the labeled neurons with precise histologically visualized hand-face border, and not its location estimated from the electrophysiological maps.

Intrinsic connections restricted to functional compartments have been observed in other systems, including visual, auditory, and motor cortex (Huntley and Jones, 1991; Yoshioka et al., 1996; Read et al., 2001; Ahmed et al., 2012). Intrinsic connections organize modules of information processing streams into networks. They show species specificity (e.g., Van Hooser et al., 2006) and are altered by cross-modal circuit manipulation dur- 
ing development, reflecting an organization consistent with the new inputs (Gao and Pallas, 1999; Sharma et al., 2000).

\section{Role of intrinsic connections in plasticity}

Intrinsic connections likely contribute to the brain reorganization (Burton and Fabri, 1995; Jones and Pons, 1998). In rat whisker barrel cortex, whisker pairing plasticity is more robust across rows compared with across arcs (Armstrong-James et al., 1994), which corresponds with richer intrinsic connections across rows than arcs (Hoeflinger et al., 1995). Similarly, intrinsic connections play a role in plasticity in the motor cortex and visual cortex (Huntley, 1997; Calford et al., 2003) and help in shaping of isoorientation tuned neuronal responses in V1 (Shushruth et al., 2012).

Because the extent of shifts in the representational boundaries in the cortex after large deafferentations, such as transection of the dorsal columns $(10-14 \mathrm{~mm}$, and sometimes more that $20 \mathrm{~mm}$, Jain et al., 2008) or transection of dorsal roots (Pons et al., 1991), is beyond what can be mediated by normal connections in the brain, reorganization must involve axonal sprouting (Kaas et al., 1999). Sprouting from spinal trigeminal nucleus into the deafferented cuneate nucleus is seen in monkeys with long-term lesions of the dorsal columns (Jain et al., 2000). We have recently shown that reorganization of the cuneate nucleus is the critical change that drives cortical reorganization (Kambi et al., 2014). However, sprouting at cortical and thalamic levels was not ruled out. Such sprouting, if present, may not be expressed physiologically (Lane et al., 1995) but could play a role in shaping the novel receptive fields of neurons resulting from reorganizational changes at the medullary level (Faggin et al., 1997; Ergenzinger et al., 1998).

There are reports of sprouting in the cortex of adult animals following injuries. For example, following chronic limb amputations in macaque monkeys, cortical spread of the tracer injected in the stump representation was more in injured monkeys compared with normal animals, suggesting the possibility of axonal sprouting in area $3 \mathrm{~b}$ (Florence et al., 1998). Sprouting was also seen in the primary visual cortex of animals with retinal lesions (Darian-Smith and Gilbert, 1994; Yamahachi et al., 2009). And in the motor cortex of adult squirrel monkeys, novel terminal fields were observed in ventral premotor cortex after M1 lesions (Dancause et al., 2005). Here we have specifically examined whether there is an increase in connectivity across the hand-face border in area $3 \mathrm{~b}$ because the goal was to determine correlates of expansion of the chin representation into the deafferented hand area. We did not find any difference in intrinsic connections between the hand and the face representations in area $3 \mathrm{~b}$. The boundary between the hand and the face representations appears to be a strong limiting boundary that does not permit sprouting across, unlike that seen within the hand representation or other cortical areas following injuries (Darian-Smith and Gilbert, 1994; Florence et al., 1998; Dancause et al., 2005). Our observations also show that the HFS is not obliterated despite deafferentation and reorganization (Jain et al., 1998b).

\section{Thalamocortical connections and brain plasticity}

Fidelity of thalamocortical connections from VPM to the face representation in area $3 \mathrm{~b}$, and hand subnucleus of VPL to the hand representation, is strong (see Steriade et al., 1997). Our data in normal monkeys conform to these observations. Injections in $\mathrm{D} 1$ representation in area $3 \mathrm{~b}$ resulted in retrogradely labeled neurons immediately lateral to the arcuate lamina separating VPM and VPL, and those in the chin representation labeled neurons immediately medial to the arcuate lamina (i.e., in the lateral-most part of VPM). These locations correspond to representations of D1 and chin in the VP nucleus (Jones and Friedman, 1982; Kaas et al., 1984; Darian-Smith et al., 1990; Burton and Fabri, 1995; Padberg et al., 2009). In monkeys with chronic lesions of the dorsal columns and cortical reorganization, locations of labeled neurons after injection of retrograde tracers medial and lateral to HFS in area 3b (i.e., in D1 and chin representations) was similar to that in normal monkeys. This suggests that there was no collateral sprouting of the thalamocortical afferents from VPM into the deafferented hand area, or VPL into the face region of area $3 \mathrm{~b}$. Previously, extensive shrinkage of VP nucleus has been reported in monkeys with dorsal root sections, which was proposed to be a likely mediator of large-scale brain plasticity (Jones and Pons, 1998). However, the recovery period of our monkeys was short, and no massive shrinkage of VP was apparent (Fig. 10). Rasmusson and Nance (1986) reported that digit amputations in raccoons do not lead to any change in the thalamocortical arbors, although there is a change in the cortical map. Thus, alteration of thalamocortical connections perhaps plays a very limited role in brain reorganization, if at all.

We have not examined intracortical connections within the hand representation, which may undergo sprouting due to inju- 
ries (Florence et al., 1998). Circuitry of the normal intrinsic connections within the hand representation as well as de novo connections as a result of the sprouting, if any, would contribute to shaping of the receptive field properties and responses of neurons to the chin stimulation resulting from subcortical reorganization. Understanding mechanisms of brain plasticity is of interest for development of brain-computer interface devices and neuroprostheses because postinjury plasticity can undermine control of devices, or if properly managed, facilitate a better interface (e.g., Enzinger et al., 2008; Jain, 2010; Collignon et al., 2011). Data presented here suggest that any intervention to prevent undesirable brain reorganization needs to be focused on subthalamic regions.

\section{References}

Ahmed B, Cordery PM, McLelland D, Bair W, Krug K (2012) Long-range clustered connections within extrastriate visual area V5/MT of the rhesus macaque. Cereb Cortex 22:60-73. CrossRef Medline

Armstrong-James M, Diamond ME, Ebner FF (1994) An innocuous bias in whisker use in adult rats modifies receptive fields of barrel cortex neurons. J Neurosci 14:6978-6991. Medline

Burton H, Fabri M (1995) Ipsilateral intracortical connections of physiologically defined cutaneous representations in areas $3 \mathrm{~b}$ and 1 of macaque monkeys: projections in the vicinity of the central sulcus. J Comp Neurol 355:508-538. CrossRef Medline

Calford MB, Wright LL, Metha AB, Taglianetti V (2003) Topographic plasticity in primary visual cortex is mediated by local corticocortical connections. J Neurosci 23:6434-6442. Medline

Cerkevich CM, Qi HX, Kaas JH (2013) Thalamic input to representations of the teeth, tongue, and face in somatosensory area $3 \mathrm{~b}$ of macaque monkeys. J Comp Neurol 521:3954-3971. CrossRef Medline

Collignon O, Champoux F, Voss P, Lepore F (2011) Sensory rehabilitation in the plastic brain. Prog Brain Res 191:211-231. CrossRef Medline

Dancause N, Barbay S, Frost SB, Plautz EJ, Chen D, Zoubina EV, Stowe AM, Nudo RJ (2005) Extensive cortical rewiring after brain injury. J Neurosci 25:10167-10179. CrossRef Medline

Darian-Smith C, Gilbert CD (1994) Axonal sprouting accompanies functional reorganization in adult cat striate cortex. Nature 368:737-740. CrossRef Medline

Darian-Smith C, Darian-Smith I, Cheema SS (1990) Thalamic projections to sensorimotor cortex in the macaque monkey: use of multiple retrograde fluorescent tracers. J Comp Neurol 299:17-46. CrossRef Medline

Dutta A, Kambi N, Raghunathan P, Khushu S, Jain N (2014) Large-scale reorganization of the somatosensory cortex of adult macaque monkeys revealed by fMRI. Brain Struct Funct 219:1305-1320. CrossRef Medline

Enzinger C, Ropele S, Fazekas F, Loitfelder M, Gorani F, Seifert T, Reiter G, Neuper C, Pfurtscheller G, Müller-Putz G (2008) Brain motor system function in a patient with complete spinal cord injury following extensive brain-computer interface training. Exp Brain Res 190:215-223. CrossRef Medline

Ergenzinger ER, Glasier MM, Hahm JO, Pons TP (1998) Cortically induced thalamic plasticity in the primate somatosensory system. Nat Neurosci 1:226-229. CrossRef Medline

Faggin BM, Nguyen KT, Nicolelis MA (1997) Immediate and simultaneous sensory reorganization at cortical and subcortical levels of the somatosensory system. Proc Natl Acad Sci U S A 94:9428-9433. CrossRef Medline

Fang PC, Jain N, Kaas JH (2002) Few intrinsic connections cross the handface border of area $3 \mathrm{~b}$ of New World monkeys. J Comp Neurol 454:310 319. CrossRef Medline

Florence SL, Taub HB, Kaas JH (1998) Large-scale sprouting of cortical connections after peripheral injury in adult macaque monkeys. Science 282: 1117-1121. CrossRef Medline

Gao WJ, Pallas SL (1999) Cross-modal reorganization of horizontal connectivity in auditory cortex without altering thalamocortical projections. J Neurosci 19:7940-7950. Medline

Gibson AR, Hansma DI, Houk JC, Robinson FR (1984) A sensitive low artifact TMB procedure for the demonstration of WGA-HRP in the CNS. Brain Res 298:235-241. CrossRef Medline

Hoeflinger BF, Bennett-Clarke CA, Chiaia NL, Killackey HP, Rhoades RW (1995) Patterning of local intracortical projections within the vibrissae representation of rat primary somatosensory cortex. J Comp Neurol 354: 551-563. CrossRef Medline

Huntley GW (1997) Correlation between patterns of horizontal connectivity and the extend of short-term representational plasticity in rat motor cortex. Cereb Cortex 7:143-156. CrossRef Medline

Huntley GW, Jones EG (1991) Relationship of intrinsic connections to forelimb movement representations in monkey motor cortex: a correlative anatomic and physiological study. J Neurophysiol 66:390-413. Medline

Iyengar S, Qi HX, Jain N, Kaas JH (2007) Cortical and thalamic connections of the representations of the teeth and tongue in somatosensory cortex of new world monkeys. J Comp Neurol 501:95-120. CrossRef Medline

Jain N (2010) Brain-machine interface: the future is now. Natl Med J India 23:321-323. Medline

Jain N, Catania KC, Kaas JH (1997) Deactivation and reactivation of somatosensory cortex after dorsal spinal cord injury. Nature 386:495-498. CrossRef Medline

Jain N, Florence SL, Kaas JH (1998a) Reorganization of somatosensory cortex after nerve and spinal cord injury. News Physiol Sci 13:143-149. Medline

Jain N, Catania KC, Kaas JH (1998b) A histologically visible representation of the fingers and palm in primate area $3 \mathrm{~b}$ and its immutability following long-term deafferentations. Cereb Cortex 8:227-236. CrossRef Medline

Jain N, Florence SL, Qi HX, Kaas JH (2000) Growth of new brainstem connections in adult monkeys with massive sensory loss. Proc Natl Acad Sci U S A 97:5546-5550. CrossRef Medline

Jain N, Qi HX, Collins CE, Kaas JH (2008) Large-scale reorganization in the somatosensory cortex and thalamus after sensory loss in macaque monkeys. J Neurosci 28:11042-11060. CrossRef Medline

Jones EG (2000) Cortical and subcortical contributions to activitydependent plasticity in primate somatosensory cortex. Annu Rev Neurosci 23:1-37. CrossRef Medline

Jones EG, Friedman DP (1982) Projection pattern of functional components of thalamic ventrobasal complex on monkey somatosensory cortex. J Neurophysiol 48:521-544. Medline

Jones EG, Pons TP (1998) Thalamic and brainstem contributions to largescale plasticity of primate somatosensory cortex. Science 282:1121-1125. CrossRef Medline

Kaas JH, Nelson RJ, Sur M, Dykes RW, Merzenich MM (1984) The somatotopic organization of the ventroposterior thalamus of the squirrel monkey, Saimiri sciureus. J Comp Neurol 226:111-140. CrossRef Medline

Kaas JH, Florence SL, Jain N (1999) Subcortical contributions to massive cortical reorganizations. Neuron 22:657-660. CrossRef Medline

Kaas JH, Qi HX, Burish MJ, Gharbawie OA, Onifer SM, Massey JM (2008) Cortical and subcortical plasticity in the brains of humans, primates, and rats after damage to sensory afferents in the dorsal columns of the spinal cord. Exp Neurol 209:407-416. CrossRef Medline

Kambi N, Tandon S, Mohammed H, Lazar L, Jain N (2011) Reorganization of the primary motor cortex of adult macaque monkeys after sensory loss resulting from partial spinal cord injuries. J Neurosci 31:3696-3707. CrossRef Medline

Kambi N, Halder P, Rajan R, Arora V, Chand P, Arora M, Jain N (2014) Large-scale reorganization of the somatosensory cortex following spinal cord injuries is due to brainstem plasticity. Nat Commun 5:3602. CrossRef Medline

Krubitzer LA, Kaas JH (1992) The somatosensory thalamus of monkeys: cortical connections and a redefinition of nuclei in marmosets. J Comp Neurol 319:123-140. CrossRef Medline

Lane RD, Bennett-Clarke CA, Chiaia NL, Killackey HP, Rhoades RW (1995) Lesion-induced reorganization in the brainstem is not completely expressed in somatosensory cortex. Proc Natl Acad Sci U S A 92:42644268. CrossRef Medline

Liao CC, Gharbawie OA, Qi H, Kaas JH (2013) Cortical connections to single digit representations in area $3 \mathrm{~b}$ of somatosensory cortex in squirrel monkeys and prosimian galagos. J Comp Neurol 521:3768-3790. CrossRef Medline

Manger PR, Woods TM, Muñoz A, Jones EG (1997) Hand/face border as a limiting boundary in the body representation in monkey somatosensory cortex. J Neurosci 17:6338-6351. Medline

Mohammed H, Jain N (2014) Two whisker motor areas in the rat cortex: evidence from thalamocortical connections. J Comp Neurol 522:528545. CrossRef Medline

Négyessy L, Pálfi E, Ashaber M, Palmer C, Jákli B, Friedman RM, Chen LM, 
Roe AW (2013) Intrinsic horizontal connections process global tactile features in the primary somatosensory cortex: neuroanatomical evidence. J Comp Neurol 521:2798-2817. CrossRef Medline

Padberg J, Cerkevich C, Engle J, Rajan AT, Recanzone G, Kaas J, Krubitzer L (2009) Thalamocortical connections of parietal somatosensory cortical fields in macaque monkeys are highly divergent and convergent. Cereb Cortex 19:2038-2064. CrossRef Medline

Pons TP, Garraghty PE, Ommaya AK, Kaas JH, Taub E, Mishkin M (1991) Massive cortical reorganization after sensory deafferentation in adult macaques. Science 252:1857-1860. CrossRef Medline

Rasmusson DD, Nance DM (1986) Non-overlapping thalamocortical projections for separate forepaw digits before and after cortical reorganization in the raccoon. Brain Res Bull 16:399-406. CrossRef Medline

Read HL, Winer JA, Schreiner CE (2001) Modular organization of intrinsic connections associated with spectral tuning in cat auditory cortex. Proc Natl Acad Sci U S A 98:8042-8047. CrossRef Medline

Reiner A, Veenman CL, Medina L, Jiao Y, Del Mar N, Honig MG (2000) Pathway tracing using biotinylated dextran amines. J Neurosci Methods 103:23-37. CrossRef Medline

Sharma J, Angelucci A, Sur M (2000) Induction of visual orientation modules in auditory cortex. Nature 404:841-847. CrossRef Medline

Shushruth S, Mangapathy P, Ichida JM, Bressloff PC, Schwabe L, Angelucci A (2012) Strong recurrent networks compute the orientation tuning of surround modulation in the primate primary visual cortex. J Neurosci 32:308-321. CrossRef Medline

Steriade M, Jones EG, McCormick DA (1997) Thalamus, Vol 1: Organization and function. Oxford: Elsevier Science.

Tandon S, Kambi N, Jain N (2008) Overlapping representations of the neck and whiskers in the rat motor cortex revealed by mapping at different anaesthetic depths. Eur J Neurosci 27:228-237. CrossRef Medline

Tandon S, Kambi N, Lazar L, Mohammed H, Jain N (2009) Large-scale expansion of the face representation in somatosensory areas of the lateral sulcus after spinal cord injuries in monkeys. J Neurosci 29:12009-12019. CrossRef Medline

Van Hooser SD, Heimel JA, Chung S, Nelson SB (2006) Lack of patchy horizontal connectivity in primary visual cortex of a mammal without orientation maps. J Neurosci 26:7680-7692. CrossRef Medline

Wong-Riley M (1979) Changes in the visual system of monocularly sutured or enucleated cats demonstrable with cytochrome oxidase histochemistry. Brain Res 171:11-28. CrossRef Medline

Yamahachi H, Marik SA, McManus JN, Denk W, Gilbert CD (2009) Rapid axonal sprouting and pruning accompany functional reorganization in primary visual cortex. Neuron 64:719-729. CrossRef Medline

Yoshioka T, Blasdel GG, Levitt JB, Lund JS (1996) Relation between patterns of intrinsic lateral connectivity, ocular dominance, and cytochrome oxidase-reactive regions in macaque monkey striate cortex. Cereb Cortex 6:297-310. CrossRef Medline 